Josef Rojter, Victoria University of Tech. 


\title{
Fundamental Sciences in Engineering Curriculum: The Case of Chemistry
}

\begin{abstract}
As a response to concerns and suggestions of the Institution of Engineers, Australia accrediting the undergraduate curriculum in mechanical engineering, the Department of Mechanical Engineering at Victoria University of Technology (VUT) decided to incorporate chemical sciences into its undergraduate curriculum. The first semester of second year materials technology subject was set aside to include topics of chemical sciences and technology. This course was eventually extended and also became an integral part of architectural, building and civil engineering curricula. Though all undergraduate engineering students at VUT had sound fundamental science background in disciplines of mathematics and physics, more than half of these students had no exposure to chemical sciences beyond that offered as part of general science curriculum at junior levels in secondary schools and colleges. This paper deals with the development of chemical syllabus and its refinement since its introduction in 1995 and is outlined in this paper.

The students' lack of previous background in chemistry combined with the lack of laboratory resources and constrained by that this course was incorporated into a two semester engineering materials subject meant that the syllabus development had to be approached in a creative way. The course was constructed in a chemical engineering way. In designing the course I assumed that all students had no prior knowledge of any chemistry and the first 25 percent of the syllabus was devoted to the fundamental knowledge of atomic theory and bonding and its effect on physical and mechanical properties of solids. The remaining part of the course was devoted to process calculations through which students were introduced to fundamentals of mass and energy balances. The context of the syllabus was the development of problem solving skills in areas of environment, energy and material manufacturing issues. Subject evaluation has shown student satisfaction with the syllabus, comparatively higher pass rates than other engineering science and fundamental science subjects and interestingly it also showed that previous background in chemistry played little or no role in students' academic performance in this subject.
\end{abstract}

\section{Introduction}

In accrediting the undergraduate mechanical engineering course at VUT (Victoria University of Technology, in 1994, the accrediting body the IE Aust. (Institution of Engineers Australia), felt that despite the adequate proportion of fundamental sciences in the existing curriculum suggested an increase in the proportion of fundamental science was needed to address poor preparation of students entering the course. After considerable internal discussion which included disciplines of mathematical and computer sciences, biological sciences and physics it was agreed that IEAust recommendations could be met by the inclusion of one semester subject that focused on chemical sciences. The inclusion of chemical sciences in the mechanical engineering curriculum was in a way counter to prevailing trends of engineering curriculum development at Australian universities where chemical sciences have experienced a marked reduction of presence in engineering curricula (with the exception of chemical engineering). It also made sense because a high proportion of our graduates destination were in manufacturing industry and environmental technologies where since chemical sciences are part and parcel of engineering practice. In a way the inclusion of chemical sciences in the curriculum anticipated the reports made by the 
Australian Science and Technology Council (ASTEC) which called for the broadening of engineering curricula through the expansion of generalist science base. ASTEC identified ${ }^{1}$ a category of generalist engineers who in the course of professional practice needed broad technical and scientific base to enable them to cross specialist engineering boundaries. Institution of Engineers Report ${ }^{2}$ on the direction of engineering education to instil engineering graduates with greater environmental awareness implicitly supported introduction of chemical sciences into the engineering curriculum.

\section{Background}

Designing of courses is, at best, a very complex exercise. In a traditional course design process learning objectives are named. In engineering education these traditionally include the understanding and mastering knowledge and skills of the subject matter, understanding the context of the subject within professional engineering discourse, development of communication skills, instilling skills in teamwork, developing autonomous and reflective practitioner with social awareness of the impact of engineering practice, and instilling skills for life-long learning. In common with many curriculum designs the course structure derives from Bloom's ${ }^{3}$ hierarchical knowledge taxonomy of learnt (memorized) knowledge, its comprehension, its application, its synthesis, and evaluation. However prior to designing the course I was confronted with two realities, these being:

- Student group; and

- Knowledge domain.

A major proportion of students enrolling in engineering at VU come from the more socioeconomically disadvantaged western and north-western regions of Melbourne. Unlike their peers in the other regions of Melbourne who have greater (socio-economic) access to well resourced private and public schools, students enrolling at VU are educationally disadvantaged and are often the first generation in their family who have completed secondary schooling. This is overlayed by the fact that the proportion of students at VU from non-English speaking background is the highest in Australia, with all the issues on cultural implications on teaching and learning. The minimum admission to engineering at VU, as measured by the ENTER score, is 10 points below the minimum entry requirements to engineering at the next least prestigious university. The normal entry into engineering courses in Melbourne-based universities require good passes, in year 12, in physics and advanced mathematics. Chemistry is not a requirement for entry into engineering, though at some universities secondary students wishing to pursue studies in chemical engineering are strongly advised to undertake chemistry at year 12 level.

Only a minority, between 29 and 34 percent of students, entering engineering courses within the school have completed year 12 chemistry and between 12 and 15 percent of students have only completed year 11 chemistry and subsequently dropping out from the subject. Some 10 percent of students, many mature students, undertake preparatory or bridging summer chemistry classes which unlike similar classes in mathematics and physics are not compulsory because it is not a prerequisite entry subject This figures vary from year to year and the types of course in which students are enrolled but the fact is minority of the students have a nominal pre-requisites to tackle a university standard chemical science subject and this has presented a major pedagogical challenge.

As the materials science and technology coordinator my task was to design the subject that it integrates into other aspects of materials and engineering curriculum. The subject thus must 
have academic and action components. As a chemical engineer I designed the subject as an engineering science rather than science subject in which chemistry was used as vehicle to develop engineering context and consciousness.

\section{The Curriculum}

The syllabus was designed on the assumption that students possessed chemical knowledge equivalent to year 9 high-school general science curriculum. This subject was to be delivered in a distinct narrative style which linked theory and principles to material technology and, more importantly, a worldview of engineering discourse. The subject was not to be a terminal one but integrated to the rest of the engineering curriculum. A minor objective of this subject was an epistemic one; to make students aware of scientific limitations and distinguish between the scientific and engineering methods. This two-pronged course design is shown in table 1 . The principles and theory provide tools through which technological applications and engineering practice are illustrated. These principles are further carried into the materials science subjects offered in the latter semesters

Table1. Syllabus construct

\begin{tabular}{|c|c|}
\hline $\begin{array}{l}\text { Subject principles } \\
\text { and theory }\end{array}$ & Action and Application \\
\hline $\begin{array}{l}\text { Conservation of } \\
\text { mass and energy }\end{array}$ & $\begin{array}{l}\text { Calculation of mass and energy balances around process units } \\
\text { involving recycle and by-pass streams. }\end{array}$ \\
\hline $\begin{array}{l}\text { Structure of atoms } \\
\text { and atomic bonding }\end{array}$ & $\begin{array}{l}\text { Relationship between the mechanical and physical properties } \\
\text { of solids and the nature of atomic and molecular bonding. }\end{array}$ \\
\hline $\begin{array}{l}\text { Stoichiometric } \\
\text { balances of chemical } \\
\text { reactions. }\end{array}$ & $\begin{array}{l}\text { Calculations around process units involving chemical } \\
\text { reactions such as combustion and smelting processes and } \\
\text { introduction to production of processes such as sulphuric acid, } \\
\text { smelting of ores, setting of cements and calculations of } \\
\text { reactions in the environment. }\end{array}$ \\
\hline $\begin{array}{l}\text { Chemical } \\
\text { equilibrium }\end{array}$ & $\begin{array}{l}\text { Extent of reactions around process units. Acid-base reactions. } \\
\text { Application to processes involving chemical equilibrium. }\end{array}$ \\
\hline $\begin{array}{l}\text { Rate of reactions and } \\
\text { reaction mechanism }\end{array}$ & $\begin{array}{l}\text { Examples from processes. Calculation of process units } \\
\text { involved in the manufacture of polymers and pharmaceuticals. } \\
\text { Illustration of reactions in atmosphere. }\end{array}$ \\
\hline Thermochemistry & $\begin{array}{l}\text { Heat balances around process units. Calculation of process } \\
\text { temperatures for material selection in chemical reactors. Effect } \\
\text { of temperature on the reversibility of reactions. }\end{array}$ \\
\hline Electrochemistry & $\begin{array}{l}\text { Application in the study of production of electricity with } \\
\text { emphasis on batch and fuel batteries. Application to corrosion } \\
\text { and corrosion protection of metals. A study in the production } \\
\text { of aluminium. }\end{array}$ \\
\hline $\begin{array}{l}\text { Studies of } \\
\text { atmospheric and } \\
\text { land pollution. }\end{array}$ & $\begin{array}{l}\text { Calculations involving current issues in fuel technology, } \\
\text { manufacturing industry, agriculture and urban transport. }\end{array}$ \\
\hline Production of steel & Full material and energy balances in production of steels. \\
\hline
\end{tabular}

The assessment of the subject is fairly flexible. Though it essentially consists of two tests contributing to 25 percent of the total subject assessment and a major three hour examination at the end of the semester which contributes to the remaining 75 percent of the subject assessment, there are built-in assessment flexibilities. Students who perform better in the 
semester examination than in the tests will have the test results replaced by scaled-up examination mark. The subject also incorporates a problem based learning (PBL) component which students can, on voluntary basis, undertake in small groups as one or two assessment tasks, from the action column in table 1 , each task contributing 15 percent to the overall subject assessment. These assessment tasks involve significant calculations and must be presented in a full report form with full bibliography and appendices. Each year these problems are selected and presented to the students in the form of materials/manufacturing, social and environmental, and product design issues which can be tackled using tools derived from the subject and further student reading and research. Given small number of problems designed each year and large number of students enrolled in this subject only a minority of students undertake this form of assessment on first come-first-serve basis. Nevertheless the major semester examination contribution to total assessment varies from 45 to 100 percent.

\section{Validation}

There is little doubt that the curriculum outlined in table 1 is relatively dense and it places a great degree of onus on the student. This needed to be done in order to include a component of PBL within the course and widen the students' appreciation of technical engineering discourses.

The students' perspective of the subject is an interesting one. In a survey conducted of 8 subjects, by one of my colleagues, on subject quality between 1996-1998 indicated that students rated this subject as among two of the most demanding and difficult subjects though interestingly students also rated the subject as the most interesting and most satisfying. In an informal Student Educational Satisfaction (SES) survey, conducted in 2005, the two questions concerning work demands placed on the student and satisfaction and enthusiasm aroused by the subject gave scores of 4.0 and 4.1 on the Likert scale ranging from 1-5.

I have, as well as for other subjects, encouraged students' evaluation of teaching and subject content using a simple Hildebrand's model ${ }^{4}$ with two extended statements. Students' evaluation used Likert's scale ranging from strongly agree ( 5 points) to strongly disagree (1 point). The average scores are shown in table 2 .

Table 2. Subject Assessment

\begin{tabular}{|l|l|l|l|l|l|l|l|l|}
\hline \multirow{2}{*}{ Statement } & \multicolumn{6}{|c|}{ Year of Assessment and average score } \\
\cline { 2 - 10 } & 1997 & 1998 & 1999 & 2000 & 2001 & 2003 & 2004 & 2005 \\
\hline $\begin{array}{l}\text { The lecturer has a good } \\
\text { command of the subject }\end{array}$ & 4.5 & 4.3 & 4.7 & 4.6 & 4.5 & 4.7 & 4.4 & 4.5 \\
\hline The subject objectives are clear. & 3.8 & 3.9 & 4.2 & 4.1 & 3.8 & 4.4 & 4.0 & 4.2 \\
\hline $\begin{array}{l}\text { Lecturer interacts well with the } \\
\text { class }\end{array}$ & 4.0 & 3.8 & 4.3 & 4.3 & 4.3 & 4.1 & 4.1 & 4.3 \\
\hline $\begin{array}{l}\text { Lecturer is accessible for } \\
\text { individual consultations }\end{array}$ & 4.1 & 3.9 & 3.9 & 3.8 & 4.0 & 3.8 & 3.9 & 4.0 \\
\hline $\begin{array}{l}\text { Lecturer arouses curiosity in the } \\
\text { subject }\end{array}$ & 4.0 & 3.8 & 4.4 & 4.1 & 4.0 & 3.6 & 4.0 & 4.0 \\
\hline $\begin{array}{l}\text { The subject widens the scope of } \\
\text { engineering knowledge }\end{array}$ & 3.8 & 3.9 & 4.2 & 4.3 & 4.1 & 3.9 & 4.5 & 4.1 \\
\hline $\begin{array}{l}\text { The subject is satisfying and } \\
\text { would recommend to others. }\end{array}$ & 4.1 & 4.2 & 4.0 & 4.0 & 4.3 & 4.0 & 4.2 & 4.1 \\
\hline
\end{tabular}

Though the first 5 statements, in table 2 above, evaluate the teacher performance what is 
interesting that in the last two statements the students are very positive about this subject and felt that it enhanced their engineering literacy and the understanding of the physical world around them.

Unlike fundamental sciences such as physics and mathematics the chemical science course did not assume prior high school knowledge in this subject and, unlike other engineering sciences, it does not rely on physical science pre-requisites. For most students, like engineering design, this subject represented new knowledge, and an introduction to different way of thinking inclusive of open-ended problems and solutions. However unlike engineering design, this subject was also concerned in establishing new directions of information processing, particularly with concept attainment ${ }^{5}$ and synectics ${ }^{6}$. Bruner defines concept attainment as a way of organizing knowledge that leads to concept development. Gordon and Pore observed that synectics represented collaborative group processing of knowledge that promoted synergy in development of critical thinking skills. The effect of previous knowledge of chemistry on student performances are shown in tables 3 and 4.

Table 3 compares student performances, with different preparations, when the subject was offered in the first semester at the second year level and table 4 deals with student performance when the subject was transferred into first semester of first year of the course.

Table 3 illustrates that there was little disparity in the subject performance between students who studied chemistry in secondary schools at the highest levels and those who have not studied chemistry before. The pass rates varied between 75 and just above 80 percent, well above the pass rates of mathematics and other engineering science subjects at second year level. The yearly variations in pass rates occurred to the variation of the mix of students between mechanical, civil, building and architectural students.

Table 3. Comparisons of student performance in second year.

\begin{tabular}{|c|c|c|c|c|c|c|c|c|}
\hline \multirow[t]{2}{*}{ Preparation } & \multirow{2}{*}{$\begin{array}{l}\text { Year of } \\
\text { Survey }\end{array}$} & \multicolumn{6}{|c|}{ GRADES (\% of student population) } & \multirow{2}{*}{$\begin{array}{l}\text { Av. } \\
\text { Score } \\
(\%)\end{array}$} \\
\hline & & HD & D & $\mathbf{C}$ & $\mathbf{P}$ & N1 & $\mathbf{N 2}$ & \\
\hline \multirow{3}{*}{ Year 12} & 2000 & 12.8 & 13.1 & 19.6 & 26.1 & 7.5 & 20.9 & 60.0 \\
\hline & 2001 & 13.2 & 15.2 & 18.9 & 26.1 & 8.1 & 18.5 & 61.2 \\
\hline & 2002 & 13.1 & 14.9 & 24.1 & 29.2 & 8.1 & 10.6 & 63.2 \\
\hline \multirow{3}{*}{ Year 11} & 2000 & 10.1 & 12.8 & 19.9 & 27.1 & 7.9 & 21.4 & 57.8 \\
\hline & 2001 & 13.1 & 12.8 & 21.6 & 27.6 & 7.9 & 16.9 & 59.5 \\
\hline & 2002 & 13.6 & 14.1 & 22.4 & 26.9 & 8.1 & 14.9 & 60.5 \\
\hline \multirow{3}{*}{ Bridging } & 2000 & 8.4 & 14.0 & 23.1 & 32.1 & 5.9 & 16.5 & 58.0 \\
\hline & 2001 & 10.7 & 13.6 & 23.6 & 31.8 & 9.5 & 10.8 & 58.1 \\
\hline & 2002 & 10.7 & 12.9 & 23.1 & 30.9 & 8.6 & 13.8 & 58.0 \\
\hline \multirow{3}{*}{ None } & 2000 & 9.9 & 10.0 & 26.1 & 33.0 & 8.0 & 13.0 & 57.6 \\
\hline & 2001 & 11.1 & 10.0 & 24.3 & 31.8 & 8.6 & 14.2 & 57.7 \\
\hline & 2002 & 10.0 & 9.9 & 24.3 & 32.1 & 9.9 & 13.5 & 56.7 \\
\hline
\end{tabular}

HD $($ High Distinction $)=80+\%$, D $($ Distinction $)=70 \%-79 \%, C($ Credit $)=60 \%-69 \%$, $\mathrm{P}($ Pass $)=50 \%-59 \%$, N1 (Fail) $=40 \%-49 \%$, N2 (Fail) $<39 \%$ 
Table 4. Comparisons of student performance in the first year.

\begin{tabular}{|c|c|c|c|c|c|c|c|c|}
\hline \multirow[t]{2}{*}{ Preparation } & \multirow{2}{*}{$\begin{array}{l}\text { Year of } \\
\text { Survey }\end{array}$} & \multicolumn{6}{|c|}{ GRADES (\% of student population) } & \multirow{2}{*}{$\begin{array}{l}\text { Av. } \\
\text { Score } \\
(\%) \\
\end{array}$} \\
\hline & & HD & D & $\mathbf{C}$ & $\mathbf{P}$ & N1 & $\mathbf{N} 2$ & \\
\hline \multirow{3}{*}{ Year 12} & 2003 & 8.8 & 8.1 & 25.2 & 31.2 & 4.0 & 26.7 & 58.2 \\
\hline & 2004 & 11.5 & 10.6 & 34.6 & 25.0 & 3.0 & 15.3 & 59.1 \\
\hline & 2005 & 12.2 & 14.6 & 29.2 & 26.8 & 4.9 & 12.2 & 61.1 \\
\hline \multirow{3}{*}{ Year 11} & 2003 & 7.2 & 7.2 & 8.6 & 22.8 & 13.2 & 41.0 & 49.1 \\
\hline & 2004 & 8.8 & 7.2 & 11.2 & 26.3 & 19.0 & 27.5 & 53.2 \\
\hline & 2005 & 10.5 & 0.0 & 10.5 & 31.6 & 26.3 & 21.1 & 54.4 \\
\hline \multirow{3}{*}{ Bridging } & 2003 & 16.2 & 3.6 & 11.2 & 32.1 & 12.5 & 24.4 & 50.1 \\
\hline & 2004 & 14.1 & 1.5 & 12.2 & 34.1 & 10.6 & 27.5 & 51.1 \\
\hline & 2005 & 22.2 & 0.0 & 11.1 & 33.3 & 11.1 & 22.2 & 50.0 \\
\hline \multirow{3}{*}{ None } & 2003 & 3.5 & 1.8 & 11.5 & 31.6 & 1.6 & 50.3 & 42.2 \\
\hline & 2004 & 3.6 & 1.8 & 10.7 & 31.6 & 0.0 & 52.3 & 43.1 \\
\hline & 2005 & 3.9 & 2.0 & 11.8 & 33.3 & 3.9 & 45.1 & 43.7 \\
\hline
\end{tabular}

HD $($ High Distinction $)=80+\%$, D $($ Distinction $)=70 \%-79 \%, C($ Credit $)=60 \%-69 \%$, $\mathrm{P}($ Pass $)=50 \%-59 \%$, N1 (Fail) $=40 \%-49 \%$, N2 (Fail) $<39 \%$

The transfer of the course into first year has not proved to be a positive thing. A variation of performance in the subject between students who have completed year 12 chemistry and those who have studied less or no chemistry in secondary schools is observed in table 4 . The results of students who undertook bridging courses are distorted by the small population of students and the mix of students. Some students who enrolled in the summer bridging course had completed year 11 chemistry, others have not done chemistry before and these included many mature students who, by-and-large, were responsible for the relatively high proportion of high distinctions.

The comparisons between tables 3 and 4 indicate that a level of maturity was required to tackle this subject. Nevertheless table 4 shows that students without prior knowledge but willingness to study can successfully complete this subject. In fact the overall pass rate for this subject was higher than pass rates in both physics and mathematics which required year 12 equivalent preparation as a pre-requisite for the course.

\section{Conclusion}

The development of professional curricula are processes of all Boyer's ${ }^{7}$ scholarshipsscholarship of discovery, meaning, application and teaching. Coates ${ }^{8}$ in discussing the role of science in the engineering curriculum observed that such science subjects can be included on need to basis as the context of the professional curriculum demanded. The post-modernist philosopher and critic Lyotard cynically observed ${ }^{9}$ that the transformation of universities as critical social institutions to ones that are utilitarian and have become an arm of governments social and economic policies can be attributed to the substitution of knowledge based seeking truth by knowledge based on application. Is it true? Is replaced by what is useful. In fact such arguments have some validity in Europe where much of the professional education was located outside traditional universities.

In Australia all professional engineering education is located in (traditional) universities. Professional curricula demand applied as well as pure knowledge in which the latter is essential in ensuring that students develop critical skills and the understanding that knowledge is not just collection of facts ${ }^{10}$. 
The inclusion of a subject dealing with chemical literacy in the undergraduate engineering curriculum as a result of accreditation pressures has proved to be a positive step. A science subject was developed from engineering science and practice perspective as a key part of professional curriculum. The course was developed on an assumption of no prior knowledge and certainly has proved to be successful at second year level and relatively successful at first year level and popular among all students. The development and implementation of this curriculum was also a personal journey in which my academic beliefs were more shaped by professional engineering discourses than academic beliefs and institutional policies. Barnett et $\mathrm{al}^{11}$ observed that divergence between such beliefs in curriculum design can lead to tensions, which in my experience are ongoing.

1. ASTEC (1996). Matching Science and Technology to Future Needs- Key Issues for Australia to 2010, Canberra.: Australian Science and Technology Council

2. Johnson, P (1996). Changing the Culture:Engineering Education into the Future, Canberra: The Institution of Engineers, Australia.

3. Bloom, B.S (1956). Taxonomy of Educational Objectives: Handbook 1, Cognitive Domain, New York: Longman.

4. Hilderbrand, M (1973). " The character and skills of the effective professor", Journal of Higher Education, 44 (4), pp.41-50.

5. Bruner, J (1961). The Process of Education, Cambridge, Mass: Harvard University Press.

6. Gordon, W.W.J., and Pore, T (1976). The Art of the Possible, Cambridge, Mass: Porpoise Books.

7. Boyer, E (1990). Scholarship Reconsidered, Washington, D.C: The Carnegie Foundation.

8. Coates, F.J (1997). “Engineer in Millenium III”, American Society of Mechanical Engineering (ASME) Worldwide Newsletter, April, pp. 8-9.

9. Lyotard, J-F (1984). The Postmodern Condition: a report on knowledge, Manchester: Manchester University Press.

10. Paulsen, M.B., and Wells, C.T (1998). "Domain differences in the epistemological beliefs of college students", Research in Higher Education, 39(4), pp365-384.

11. Barnett, R., Parry. G., and Coate, K (2001). "Conceptualising Curriculum Change", Teaching in Higher Education, 6 (4), pp435-449. 


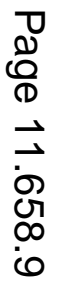

